\title{
Colibacilosis en gallinas reproductoras
}

\author{
Colibacillosis in breeding hens \\ Colibacilose em galinhas reprodutoras \\ Díaz María del Pilar ${ }^{1}$ y González Paya Gustavo Gratiniano² \\ ${ }^{1} \mathrm{MVZ}$, Universidad de los Llanos, ${ }^{2} \mathrm{MV}$, Esp. Docente Universidad de los Llanos \\ ggonzalez@unillanos.edu.co
}

Recibido 03 de Septiembre 2018, Aceptado 20 de Noviembre 2018

\section{RESUMEN}

La colibacilosis en gallinas reproductoras se da por la bacteria Gram negativa, enterobacteria Escherichia coli patogénica aviar (APEC), la cual presenta un porcentaje alto de polimorfismos y plasticidad en su genes, las investigaciones reportan hallazgos macroscópicos comunes: salpingitis, peritonitis y poliserositis, que conlleva a la muerte del ave, se definen tres rutas de contaminación, de forma ascendente por la cloaca del ave, ingreso por vía respiratoria o por translocación bacteriana desde el intestino; el diagnóstico de la colibacilosis se realiza a partir del historial del galpón, realizando necropsias y tomando muestras a partir de hisopos o tejido de órganos como oviducto, pulmón, corazón u otros órganos afectados, que se llevan a medios como McConkey, eosina-metileno azul o agar drigalki para su aislamiento, como pruebas específicas para Esceherichia coli se conocen métodos basados en fenotipos como serotipo de $\mathrm{O} / \mathrm{H}$ inmunológico, tipificación de bacteriófago, electroforesis con enzimas multilocus, desorción/ionización láser asistida por matriz (MALDI-TOF) y métodos basados en genotipos como polimorfismo de longitud de restricción (RFLP), ensayo de suspensión basado en liminex, polimorfismo de longitud de fragmentos amplificados (AFLP) y mapeo óptico. Las vacunas para esta bacteria no se han desarrollado a la perfección ya que presenta respuesta inmune ante sus homólogos, pero nada de resistencia a desafíos con heterólogos, sigue en investigación el desarrollo de vacunas que puedan presentar respuesta ante varios serotipos de la bacteria, por ahora la forma 
eficaz de controlar la bacteria es a partir de protocolos de bioseguridad y prevención para la mantener la sanidad de la granja.

Palabras clave: Escherichia coli, salpingitis, peritonitis, diarrea, prevención.

\section{ABSTRACT}

The colibacillosis in breeding hens is given by Gram negative bacteria, avian pathogenic enterobacteria Escherichia coli (APEC), which presents a high percentage of polymorphisms and plasticity in its genes, research reports common macroscopic findings: salpingitis, peritonitis and polyserositis, which entails at the death of the bird, three routes of contamination are defined, ascending through the cloaca of the bird, entry by respiratory way or bacterial translocation from the intestine; the diagnosis of colibacillosis is made from the history of the chicken coop, making necropsies and taking samples from swabs or tissue from organs such as oviduct, lung, heart or others affected organs are carried to means such as McConkey, eosin-methylene blue or drigalki agar for their isolation, as specific tests to Esceherichia coli are known methods based in phenotypes such as serotyping of immunological $\mathrm{O} / \mathrm{H}$, bacteriophage typing, electrophoresis with multilocus enzymes, Matrix-Assisted Laser Desorption/Ionization (MALDI-TOF) and methods based on genotypes such as restriction length polymorphism (RFLP), liminex-based suspension assay, amplified fragment length polymorphism (AFLP) and optical mapping. The vaccines for this bacterium have not been developed to perfection because it presents an immune response to its homologous, but no resistance to challenges with heterologous, is still researching the development of vaccines that may present a response to several serotypes of the bacteria, for now the effective way to control the bacteria is from of biosafety and prevention protocols to maintain the health of the animal.

Keywords: Escherichia coli, salpingitis, peritonitis, diarrhea, prevention. 


\section{RESUMO}

Colibacilose em galinhas reprodutoras é causada pela bactéria Gram-negativa, enterobactéria Escherichia coli aviária de alta patogenicidade (APEC), a qual apresenta uma elevada percentagem de polimorfismos e plasticidade em seus genes, as investigações relatam achados macroscópicos comuns: salpingite, peritonite e poliserosite, o que leva à morte do pássaro, três rotas de poluição são definidas, subindo pela cloaca do pássaro, entrada por via respiratória ou por translocação bacteriana do intestino; o diagnóstico de colibacilose é feito a partir da história do galinheiro, realizando necropsias e tomando amostras de cotonetes ou tecido de órgão, como oviduto, pulmão, coração ou outros órgãos afetados, que são levados para meios como McConkey, eosina-metileno azul ou agar drigalki para seu isolamento, como testes específicos para Esceherichia coli são conhecidos métodos baseados em fenótipos como sorotipo O/H imunológico, tipagem de bacteriófagos, eletroforese com enzimas multilocus, dessorção/ionização laser assistido por matriz (MALDI-TOF) e métodos baseados em genótipos como o polimorfismo de comprimento de restrição (RFLP), ensaio de suspensão baseado em Liminex, polimorfismo de comprimento de fragmento amplificado (AFLP) e mapeamento óptico. As vacinas para esta bactéria não foram desenvolvidas à perfeição porque apresentam uma resposta imune aos seus homólogos, mas nenhuma resistência a desafios com heterólogos, ainda está sob investigação o desenvolvimento de vacinas que podem responder a vários sorotipos da bactéria, por agora a maneira eficaz de controlar a bactéria é a partir de protocolos de biossegurança e prevenção para manter a saúde da fazenda.

Palavras-chave: Escherichia coli, salpingite, peritonite, diarréia, prevenção.

\section{INTRODUCCIÓN}

La industria avícola comprende dos tipos de producción: carne y huevo, lo cual implica dos mercados distintos, que da origen a diferentes tipos de organizaciones, cuyo diseño y estructura de modelo de negocio también difieren. En las gallinas reproductoras se maneja un porcentaje del material genético para la producción de 
pollo de engorde; en Colombia se manejan dos líneas de reproductoras, Cobb y Ross, cada una con características genotípicas para rendimiento y conversión del alimento en carne.

Con el fin de evitar enfermedad en las aves, la avicultura se rige por procesos de bioseguridad estrictos para controlar el ingreso de patógenos a las granjas, pero existen microorganismos que son habitantes normales del ave, y que durante un desequilibrio en su salud pueden producir enfermedad, es el caso de Echerichia coli bacteria Gram negativa, hospedero natural que en condiciones de estrés produce enfermedad causando gran mortalidad y bajos índices de producción. $E$ coli puede causar daño en las reproductoras al iniciar su etapa productiva, cuyas principales lesiones son: salpingitis, peritonitis, salpingoperitonitis; lo cual implica una disminución en la producción de huevo fértil, mayor contaminación en la incubadora, aumento en el tiempo de la ventana de nacimiento por aumento de la muerte embrionaria, e inconformidad de los clientes por muerte temprana de los pollitos de engorde (Barnes y Gross, 1997).

En el sector avícola las enfermedades bacterianas como la colibacilosis son un desafío que enfrentan los veterinarios y productores, por la alta inversión y pérdidas económicas que representan, por ello se implementan protocolos de bioseguridad y normas sanitarias que se deben cumplir estrictamente, por ese motivo es necesario realizar una revisión literaria del desarrollo, causas y prevención que se deben tener en cuenta con Escherichia coli y así mejorar la comprensión de la enfermedad.

\section{GENERALIDADES DE Escherichia coli}

Theodor Escherichia fue pediatra y microbiólogo, reportó el primer aislamiento y caracterización de la bacteria, dándole el nombre de Bacterium coli commune. El organismo fue descrito después con diferente sinónimos e interacciones por diferentes investigadores, hasta que en 1954 se le reconoció como Escherichia coli (Croxen et al., 2013). 
E. coli se ha convertido en uno de los organismos modelo para investigaciones en los cuales se utilizan cepas de laboratorio y estudios comparativos y analíticos (Breland et al., 2017). Hasta la fecha, más de 3600 genomas de E. coli, se han secuenciado en parte o en su totalidad, revelando siete grupos filogenéticos: $A, B 1$, B2, C, D, E, y F con los subtipos no clasificados en un octavo grupo (Clermont et al., 2013).

\section{Evolución de E. coli}

Las cepas de $E$. coli presentan filogenéticamente cinco grupos principales a saber, A, B1, B2, D y E; Escheria coli enteroinvasiva (EIEC) también forma filogrupos adicionales, aunque los patotipos no siempre se agrupan en el mismo filogrupo, por ejemplo las cepas híbridas de E. coli enteronegativa (EAEC) y E. coli productora de toxina Shiga (STEC), E. coli patógena extraintestinal (ExPEC) o E. coli patógena aviar (APEC), y E. coli enterotoxigenica (ETEC) se han aislado en humanos y animales (Croxen et al., 2013).

El tamaño del genoma de E. coli puede diferir hasta en un millón de pares de bases, entre los comensales y las variantes patógenas, este contenido genético adicional puede contener los genes de virulencia (Touchon et al., 2009). La genómica comparada ha demostrado que los genomas de E. coli se dividen entre un conjunto de genes compartidos y conservados, denominado genoma central, y un conjunto de genes flexible llamado pangenoma; una comparación reciente de 186 genomas de E. coli encontró 1.700 grupos de genes homólogos compartidos en todos los genomas y un pangenoma de 16.400 grupos de genes (Kaas et al., 2012). Por lo tanto, la patogenicidad de $E$. coli está otorgada por el conjunto de genes flexibles, a través de la ganancia y pérdida de material genético, en varios puntos del genoma (Croxen et al., 2013).

El polimorfismo de la bacteria sugiere que la virulencia es la fuerza que impulsa la recombinación frecuente que se produce en $E$. coli, manteniendo bajas frecuencias de recombinación homóloga, pero que en ocasiones puede adquirir nuevos genes dando como resultado virulencia por intercambio genético horizontal (HGT); el 
resultante tiene mayor exposición a las defensas inmunes del hospedero, que a su vez selecciona variantes que pueden evadir esas defensas, la selección de tales variantes da como resultado tasas de mutación y recombinación más altas (Hacker y Kaper, 2000).

La mayoría de veces $E$. coli coloniza el tracto gastrointestinal de los humanos y otros mamíferos, y son parte de la flora normal del organismo, sin embargo, la adquisición de elementos genéticos, principalmente a través de la transferencia horizontal de genes da lugar a $E$. coli patógenas con distintos factores de virulencia (Breland et al., 2017). Los patotipos de $E$. coli gastrointestinales o diarreicos incluyen adherentes difusamente (DAEC), enteroagregativos (EAEC), enterohemorrágicos (EHEC), enteroinvasivos (EIEC), enteropatógenos (EPEC) y enterotoxigénicos (ETEC), han surgido también patotipos de E. coli patógenos extraintestinales (ExPEC), incluyendo E. coli patogénica aviar (APEC), E. coli causante de meningitis neonatal o asociada a meningitis (NMEC/MAEC) y E. coli uropatógena (UPEC); las constantes mutaciones que ocurren en los serotipos de $E$. coli han causado resistencia frente a los antimicrobianos, lo cual ha llevado a ocupar un papel importante en la incidencia y letalidad de las infecciones extraintestinales (Breland et al., 2017; Russo y Johnson, 2000).

\section{Escherichia coli patogénica aviar}

APEC es un importante patógeno en la industria avícola, considerado miembro patogénico de ExPEC, que puede infectar a pollos de engorde, pavos y gallinas en postura, causando la enfermedad denominada colibacilosis; las cepas de APEC inducen una amplia gama de infecciones localizadas y sistémicas, siendo una de las principales causas de mortalidad y morbilidad asociadas con grandes pérdidas económicas en la industria en todo el mundo (Zhuang et al., 2014).

La relación genética que tienen las APEC y las ExPEC está asociada con enfermedades humanas, sumado a la evidencia de modelos animales experimentales que han llegado a sugerir que las APEC pueden representar un riesgo zoonótico (Guabiraba y Schouler, 2015; Moulin et al., 2007). 
La mayoría de las enfermedades asociadas a APEC son secundarias a factores ambientales y predisposición del hospedero, por lo tanto, las pérdidas debidas a estas enfermedades pueden reducirse considerablemente controlando estos factores, actualmente APEC se reconoce como patógeno primario en lugar de una consecuencia de infecciones virales o inmunosupresiones, aunque el conocimiento de APEC y su patogénesis es limitado debido a su gran diversidad y plasticidad genética (Collingwood et al., 2014).

\section{EPIDEMIOLOGÍA}

E. coli son habitantes normales del tracto digestivo de muchas especies de aves, aunque, también colonizan el tracto respiratorio superior (faringe y tráquea) y pueden aislarse en plumas, dependiendo del nivel de contaminación ambiental (Gross, 1994). La contaminación de las aves con E. coli ocurre en las primeras horas después de la eclosión, las cepas se multiplican rápidamente en el intestino, y muchas cepas diferentes se pueden adquirir durante la vida, la contaminación vertical resulta de la transmisión de las reproductoras, en el momento de la salida del huevo por la cloaca, o in ovo, como resultado de la salpingitis (Piercy y West, 1976), la contaminación horizontal ocurre por contacto con otras aves a través de las heces, agua contaminada y alimento, aunque las aves se contaminan frecuentemente por inhalación de partículas presentes en el polvo que pueden contener hasta $10^{6}$ UFC de bacterias por gramo (Dho-Moulin y Fairbrother, 1999). La prevalencia de infecciones por E. coli en aves de corral es alta, en las gallinas ponedoras las lesiones incluyen salpingitis, peritonitis y salpingoperitonitis (Collingwood, 2016; Jordan et al., 2005).

La mortalidad en pollos recién eclosionados suele atribuirse a infecciones por APEC, mientras que los brotes de APEC en pollos de engorde resultan en tasas de mortalidad de hasta $20 \%$, y en aves que no muestran signos evidentes de infección pueden observarse lesiones en el momento del sacrificio; anteriormente se pensaba que las infecciones por $E$. coli en pollos ocurrían después de la infección primaria por virus como Newcastle u otros microrganismos como Mycoplasma, sin embargo hoy se reconoce que las infecciones por APEC pueden ser primarias, siendo sus 
factores predisponentes: estrés, exposición a amoníaco y polvo, agua contaminada, y razas modernas de rápido crecimiento son especialmente susceptibles (Barnes et al., 2008).

\section{Factores de virulencia}

Varias investigaciones han aportado conocimientos sobre los mecanismos patogénicos expresados por los patotipos APEC, los factores de virulencia que se han descrito incluyen adhesinas, toxinas, sistemas de absorción de hierro y resistencia al suero del hospedero (Nakazato et al., 2009).

- Adhesinas: La adhesión bacteriana al epitelio es importante para el establecimiento de la infección, porque permite el enlace bacteriano y contacto cercano con el hospedero; las adhesinas interactúan con receptores específicos, aunque la presencia de una adhesina no significa que la bacteria pueda adherirse a todas las superficies (Collingwood, 2016).

- Fimbria F1: Se caracteriza por su capacidad para unirse a la D-manosa, y por ende a diferentes tipos de células eucarióticas, incluyendo células intestinales, pulmonares, vesicales, epiteliales, renales y diversas células inflamatorias ( $\mathrm{La}$ Ragione y Woodward, 2002).

- Fimbria P: Denominada así por el pili o antígeno sanguíneo P asociado a la pielonefritis; se ha descrito principalmente en E. coli uropatógena humana, ocasionalmente en aislados urinarios caninos, en septicemia porcina y en APEC; se ha establecido que las fimbrias se expresan in vivo en las infecciones del tracto urinario y en los alvéolos de los pollos (Collingwood, 2016). Pourbakhsh et al., (1997) sugirieron que las fimbrias podrían estar involucradas en la colonización de los órganos sistémicos y la subsecuente septicemia. El papel de las fimbrias $P$ en la patogenicidad de APEC aún no se ha aclarado, pero se sugiriere que estas adhesinas no serían importantes para la colonización inicial del tracto respiratorio superior, aunque sí lo serían en las últimas etapas de infección, y también podría estar involucrada en la transformación de cepas avirulentas en virulentas (Kariyawasam et al., 2006). 
- Curly fimbria: Se cree que están involucrados en la supervivencia de la bacteria fuera del huésped y también desempeñan un papel en la colonización temprana (Olsen et al., 1993). Se encuentran en la superficie celular y son responsables del enlace bacteriano con proteínas de la matriz extracelular, y de la supervivencia en el ambiente externo (Olsén et al., 1993). Se cree que participan en la virulencia de ExPEC a través de interacciones con el complejo mayor de histocompatibilidad (MHC), encontrado en la mayoría de los tipos de células de mamíferos o mediante interacciones con proteínas de matriz y plasmáticas (Collingwood, 2016).

- Fimbria S: Se cree que intervienen en el cruce de la barrera hematoencefálica y también se adhieren a las células epiteliales del tracto urinario humano, lo cual sugiere un papel en la infección del tracto urinario; hasta el momento, no se ha sugerido ningún papel para la fimbria $S$ en las infecciones de APEC, sin embargo, se produce esporádicamente en patotipos APEC con una prevalencia entre 5 y $10 \%$, por lo tanto, puede desempeñar un papel en las infecciones de especies de aves, y también puede presentar un riesgo zoonótico para los humanos (Wright y Hultgren, 2006).

- Flagela: La mayoría de APEC son flagelados y móviles; los flagelos son apéndices superficiales finos, que se encuentran en una variedad de bacterias Gram negativas y positivas, que confieren movilidad en medios acuosos, tienen aproximadamente $150 \mu \mathrm{m}$ de longitud y $20 \mathrm{~nm}$ de diámetro, con una disposición de 5 a 10 flagelos por célula (Nakazato et al., 2009). Los flagelos también promueven la penetración bacteriana del moco intestinal in vivo, que puede atribuirse a la motilidad activa guiada por la quimiotaxis a lo largo de un gradiente de toxina, para acercarse a las células epiteliales subyacentes; las bacterias deben atravesar la capa de moco, que actúa como un sitio inicial para la adhesión bacteriana, como barrera protectora, como fuente de nutrientes y matriz para la replicación bacteriana, colonización e infección (Collingwood et al., 2014).

- Cápsula: Algunas cepas de E. coli tienen una cápsula de ácido Nacetilmurámico en su superficie celular que puede interactuar con los 
activadores C3 y C3b en las vías del complemento clásico y alternativo, que confiere resistencia inmune a las bacterias y que induce la resistencia inmune, el antígeno capsular K1 se asocia frecuentemente a patotipos de APEC que pertenecen a los serogrupos $\mathrm{O} 1, \mathrm{O} 2 \mathrm{y}$ a cepas no tipificables (Pourbakhsh et al., 1997).

- Resistencia sérica: Es la resistencia bacteriana al complemento, mediada por estructuras superficiales bacterianas como LPS, cápsula, colicina Col V y proteínas de membrana externa, y se ha asociado con cepas de APEC; el factor Iss (aumento de la supervivencia sérica) está asociado con la patogenicidad de APEC puesto que el gen iss se ha encontrado con mayor frecuencia entre cepas patógenas que no patógenas (Nakazato et al., 2009).

- Hemaglutinina sensible a la temperatura (TSH): La TSH es una proteína autotransportadora de serina-proteasa que se sintetiza como un precursor de $140 \mathrm{KDa}$, y se divide en dos subunidades en el periplasma bacteriano: una subunidad de $33 \mathrm{KDa}$ que permanece insertada en la membrana externa y funciona como un dominio del pasajero y otra subunidad con $106 \mathrm{KDa}$ que se secreta al ambiente extracelular la cual permanece temporalmente en la membrana externa y media la adhesión bacteriana durante las etapas iniciales de la infección, después de su secreción, la subunidad de 106 KDa probablemente presenta una actividad proteolítica, lo cual convierte a la proteína TSH en una proteína bifuncional con actividades adhesivas y proteolíticas (Mellata et al., 2003).

- Sistema de trasportadores de metales: Metales tales como hierro, zinc, níquel y cobre son esenciales para muchos procesos celulares, la concentración de estos iones metálicos dentro del citoplasma debe ser estrictamente regulada, si la concentración de hierro es demasiado baja, ciertas metaloproteínas y enzimas estarán inactivas, mientras que una concentración demasiado alta causará toxicidad (Waldron et al., 2009).

- Toxinas: Las bacterias secretan sustancias en su ambiente con diferentes propósitos, como descomponer las sustancias para absorber, metabolizar y dañar otros microorganismos, para reducir la competencia por los recursos, 
para comunicarse con otras bacterias, y para mejorar su capacidad de colonizar un hospedero o permitir el movimiento hacia un nicho diferente (Collingwood, 2016). Algunas cepas de APEC pueden producir toxinas como enterotoxina labil al calor (LT) y enterotoxina resistente al calor (ST), y las verotoxinas conocidas como toxinas Shiga, además se ha descrito también una toxina vacuolizante expresada por APEC (Ewers et al., 2004).

- Colicinas: Son proteínas expresadas por E. coli que inhiben el crecimiento bacteriano de la misma especie o especies relacionadas, se componen de dos subunidades, una que provoca lesiones de células bacterianas y otra que protege a la bacteria contra sus propias colicinas, las colicinas pueden ser codificadas por genes localizados en plásmidos, la mayoría de las cepas de APEC tienen plásmidos de colicina V (Collingwood, 2016).

\section{SÍNDROME DE PERITONITIS, SALPINGITIS Y PERISALPINGITIS POR Escherichia coli EN GALLINAS REPRODUCTORAS}

E. coli es considerado como el agente etiológico de mayor causa de salpingitis y peritonitis en gallinas, en las aves adultas puede infectar el aparato reproductivo, mientras que la infección temprana es asintomática, y es responsable de alta mortalidad embrionaria en las plantas de incubación (Gross, 1994).

\section{Genómica aviar}

En las aves la colibacilosis produce una alta morbilidad y mortalidad; en todo el mundo la enfermedad se asocia con los serotipos $\mathrm{O} 1, \mathrm{O} 2$ y 078 , los dos últimos constituyen alrededor del $80 \%$ de los casos. Las bacterias involucradas varían según el origen clonal, lo que lleva a un alto grado de diversidad en el pangenoma, sin embargo, hay varios factores de virulencia que son conservados en todas las cepas APEC, uno de ellos es el plásmido ColV grande, este plásmido porta muchos genes asociados a la virulencia que junto con los genes de virulencia transmitidos en el cromosoma promueven la patogénesis (Guabiraba y Schouler, 2015).

Huja et al., (2015) realizaron un análisis genómico de las cepas de APEC aisladas en aves con colisepticemia que representa los principales serotipos septicémicos 
aviares $\mathrm{O} 78$ y $\mathrm{O} 2$, observando que APEC constituyen un grupo de bacterias que son filogenéticamente distantes, aunque causan la misma enfermedad y tienen factores de virulencia similares.

El genoma de E. coli tiene un alto grado de plasticidad, de los muchos aislamientos secuenciados completamente, se comparte un núcleo central genómico de alrededor de 2000 genes y un pangenoma que presenta más de 18.000 genes, el cual permite un gran grado de flexibilidad y adaptación a través de la transferencia horizontal de genes (Touchon et al., 2009). La secuenciación del se relaciona con la patogenicidad que puede presentar el serotipo, dependiendo de las características de supervivencia que tenga en el hospedero. En un estudio realizado por Ewers et al., (2004) evaluando las principales serogrupos aislados en la colisepticemia de la industria avícola, encontraron la distribución así: O1 (6\%), O2 (28\%), O78 (14.7\%) y comensales $(50.4 \%)$; los siguientes genes fueron identificados con una alta prevalencia: fimC $(92.0 \%)$, iss (82.7\%), colV $(62.7 \%)$, iucD (78.0\%) y la combinación de fyuA e irp2 (71.3\%), los genes tsh (53.3\%) y vat (48.7\%) estuvieron presentes en aproximadamente la mitad de las cepas, y en menor prevalencia se identificó astA (20.0\%) y papC (22.7\%) en las cepas septicémicas.

\section{Patogénesis aviar}

Las condiciones biológicas y ambientales, así como las infecciones virales o de micoplasmas, el hacinamiento y la mala ventilación, predisponen a las aves a infecciones por E. coli (Gross, 1994). Las cepas de APEC pertenecen a clones y serogrupos limitados, siendo los más comunes y generalizados 01, O2 y O78, asociándose varios factores de virulencia potenciales con APEC, que incluyen las fimbrias tipo 1 (F1A), P (F11), curli y el sistema secuestrante de hierro de aerobactina K1 (Mellata et al., 2003).

Han sido reconocidas tres rutas de infección: el ascenso de las bacterias por la cloaca al oviducto, la infección por el tracto respiratorio y la colonización del tracto gastrointestina; y se describen tres pasos de la bacteremia: colonización, adquisición de nutrientes e inmunoevasion: 
- Colonización: Se encuentran, adhesinas (fimbrias tipo 1, fimbrias Curly, fimbria $P$, YqiStg fimbria, adhesina autotrasportadora AatA) que son proyecciones que se adhieren a la mucosa del hospedero y producen la colonización.

- Adquisición de nutrientes para su sobrevivencia, las cepas de APEC secuestran iones férricos de las proteínas ligadoras de hierro, elemento fundamental requerido para la respiración y síntesis de ADN. Los factores de virulencia tienen afinidad por quelantes de hierro como la aerobactina, salmochelin y sistema sit, que es una proteína trasportadora ChuA, que se encargan del crecimiento bacteriano dentro de los fluidos biológicos del hospedador, en los que el hierro, tiene bajas concentraciones.

- La inmunoevasion que presenta la APEC para no ser atacada por la fagocitosis y leucocitos del hospedero se da a partir del polisacárido capsular K1 con resistencia sérica y el sistema de secreción degenerador tipo III, dos factores de virulencia que conllevan a la patogénesis y la causa de la enfermedad en las gallinas reproductoras (Lutful et al., 2017).

Como se mencionó anteriormente, hay varias rutas de entrada para infectar el tracto reproductivo de las hembras, una de ellas es la contaminación por las heces presentes en la cloaca pueden resultar en un proceso ascendente hacia la vagina y hacia las secciones restantes del oviducto, puesto que la producción intensiva de huevos y la actividad estrogénica asociada predisponen a las gallinas a relajar el esfínter entre la vagina y la cloaca causando salpingitis, y si la pared del oviducto de las gallinas con salpingitis se ve comprometida puede producirse invasión peritoneal por APEC, lo que puede conducir a salpingoperitonitis. La patogénesis de la enfermedad se da por la capacidad de las bacterias para adherirse y colonizar los tejidos del hospedero (Barnes et al., 2008; Landman y Cornelissen, 2006).

Las propiedades de adherencia de las cepas de E. coli in vitro, presentan mayor adherencia al epitelio ciliado, en los oviductos de las reproductoras adultas (50 semanas) en comparación con los de las aves jóvenes (12 semanas de edad) (Monroy et al., 2005). La salpingitis afecta a las aves adultas en producción cuando ya se ha producido la citodiferenciación del oviducto a partir de la producción de 
hormonas, la diferencia en las propiedades de adherencia puede estar asociada con dicha diferenciación, dado que el epitelio maduro presenta diferentes tipos de células epiteliales, es probable que ciertas proteínas presentes en la membrana celular permitan la unión con E. coli. La presencia de cilios en la mucosa diferenciada también podría estar involucrada en la adherencia bacteriana (Barnes y Gross, 1997).

La infección del tracto respiratorio de las aves por APEC ocurre a través de la inhalación de partículas de aerosol contaminado, las bacterias inhaladas en el pulmón son atacadas por los macrófagos, primera línea de defensa del organismo y medio de diseminación de la bacteria, las APEC son fagocitadas por células epiteliales auriculares e infundibulares de la región parabronquial. El saco aéreo no tiene mecanismos de defensa celular conocidos y depende de la afluencia inflamatoria de neutrófilos, como parte de la primera línea de defensa celular, por tanto, las regiones de intercambio de aire de los pulmones y sacos aéreos son vulnerables a la colonización bacteriana. La región aire-capilar del pulmón, es un sitio importante de entrada de $E$. coli al torrente sanguíneo de las aves, después de colonizar tráquea y sacos aéreos se considera que los siguientes órganos afectados son el pericardio e hígado causando bacteremia (Dho-Moulin y Fairbrother, 1999).

Los pulmones de las aves poseen parabronquios, estructuras que permiten el flujo unidireccional del aire a través del pulmón, los cuales están en contacto cercano con los capilares sanguíneos, es decir un área para el intercambio de gases en el sistema respiratorio aviar donde el aire entra y sale por distensión y compresión, el aire puede entrar y salir del pulmón, pero también permanecer en los parabroquios, lo cual puede favorecer la colonización bacteriana de las vías respiratorias inferiores del ave. La colibacilosis pulmonar es prevalente, sin embargo, células residentes podrían ayudar a reconocer y eliminar las bacterias invasoras en los pulmones de las aves, tanto los macrófagos como las células dendríticas están presentes en la mucosa de las vías respiratorias más grandes (Guabiraba y Schouler, 2015). 


\section{Respuesta inmune del hospedero}

Diversos niveles de defensa del hospedador se desarrollan, dependiendo del número de organismos que ingresan y de la virulencia que presenten; sí el tamaño del inoculo y la virulencia son bajos, los fagocitos tisulares son capaces de eliminar la bacteria, mientras que organismos con mayor virulencia inducen una reacción inmunitaria específica y adaptativa en el animal (Kindt et al., 2007). Las bacterias extracelulacelulares producen endotoxinas como los lipolisacaridos, que son componentes de la pared celular bacteriana que producen una respuesta inmune básica.

Para responder a un microorganismo invasor, las células inmunes receptoras responden a través de receptores como los Toll-like (TLR) que distinguen diferentes clases de patrones moleculares asociados a patógenos (PAMP), la activación microbiana de las células inmunitarias inducida por el patógeno conduce a la activación de vías de señalización intracelular relacionadas con los mecanismos de destrucción microbiana y la producción de citosinas (Guabiraba y Schouler, 2015). Las funciones de los macrófagos incluyen: fagocitosis de partículas extrañas, secreción de enzimas y metabolitos oxidativos, producción de citocinas involucradas en la respuesta proinflamatoria como interleucinas (IL1, IL6) y factor de necrosis tumoral (TNFa), y opsonización, además también tienen un papel importante en la activación de la respuesta inmune celular (Sun et al., 2016). Las células natural killer (NK) tienen características similares a las células T citotóxicas, puesto que ambas responden contra una amplia variedad de patógenos mediante la producción de serina proteasa, que es una proteína formadora de poros; estas células desempeñan un papel clave en la defensa primaria del hospedero y en la homeostasis de los tejidos normales como parte del sistema inmune innato (Yoder y Litman, 2011).

\section{Hallazgos patológicos}

La infección por E. coli incluye septicemia, pericarditis subaguda, aerosaculitis, salpingitis y peritonitis; muchos serotipos se encuentran en las aves de corral, pero 
solo APEC posee factores de virulencia específicos y es capaz de causar salpingitis y peritonitis, lesiones que pueden ser causadas por una infección sistémica o ascendente del oviducto desde la cloaca (Landman y Cornelissen, 2006); suele encontrarse exudados fibrinosos en la vagina y oviducto (itsmo, utero), ovarios atrofiados y mucosa del oviducto engrosada y edematosa (Ozaki y Murase, 2009; Roberts et al., 2011).

A nivel microscópico, los procesos inflamatorios causados por APEC llevan a necrosis y acumulación de fibrina en los tejidos. En un estudio realizado por Chaudhari y Kariyawasam, (2014) con modelos de infección experimental con $E$. coli $\mathrm{O} 78$ en reproductoras pesadas se observaron lesiones en el tejido ovárico con engrosamiento de la membrana perivitelina, reemplazo de células de la granulosa por células inflamatorias y presencia de colonias bacterianas.

\section{EFECTO SOBRE LA PRODUCCIÓN}

La infección del oviducto por E. coli causa alta mortalidad en las reproductoras, disminución de la producción de huevo, contaminación de huevos fértiles, aumento en la mortalidad embrionaria o en la primera semana de vida del pollo de engorde (Barnes et al., 2008). La entrada del microorganismo tiene lugar en diferentes sitios del sistema de producción, hay transmisión horizontal en las incubadoras y en la línea de procesamiento en el criadero pudiendo afectar a polluelos; el transporte de pollos y la higiene de la granja también son puntos críticos que presentan un riesgo de transmisión (Yassin et al., 2009). La transmisión vertical es una importante ruta para los genes que confieren resistencia a los antimicrobianos (Olsen et al., 2012; Petersen et al., 2006).

\section{Trasmisión a la progenie}

Se considera que la transmisión vertical de agentes infecciosos generalmente ocurre por el oviducto antes de la formación de la cáscara del huevo, E. coli es capaz de penetrar la cáscara de huevo y ha sido aislado de huevos fértiles (Olsen et al., 2012). También se ha demostrado la transmisión vertical para otras especies 
bacterianas tales como Salmonella enterica y Enterococcus faecalis (Landman et al., 1999).

Wang et al., (2018) evaluaron la muerte embrionaria después de la inoculación de dos cepas de E. coli (ST95 y ST141) encontrando que todos los embriones murieron a las 48 horas post inyección, destacando la habilidad que tiene $E$. coli para penetrar la cascara del huevo y así poder desarrollar una ruta de infección y alterar el desarrollo del embrión.

Factores como la diferencia de temperatura entre el huevo y suspensión bacteriana, el $\mathrm{pH}$ de la misma, la concentración bacteriana, la humedad y la calidad de la cáscara pueden influir en la tasa de penetración bacteriana en la cáscara. La calidad de la cáscara disminuye durante la vida de la gallina ponedora, lo que resulta en una mayor tasa de huevos contaminados en aves mayores a 45 semanas; se ha reportado que la deposición de la cutícula, es un factor que influye en la tasa de penetración de la bacteria a la cáscara de huevo, mientras que otros factores como el grosor de la cáscara y el número de poros en la cáscara no contribuyen significativamente en la misma (De Reu et al., 2006).

Poulsen et al., (2017) encontraron que la mayor prevalencia de colonización de $E$. coli se presenta en el huevo de piso y que fue significativamente mayor $(P<0.05)$ a la de los huevos puestos en nido, esto podría sugerir que, excluir los huevos del piso de la nacedora podría minimizar la infección de los pollos recién nacidos con E. coli. Estos mismos autores encontraron que pollitos de padres con mayor edad presentaban mayor riesgo de contaminarse que los de padres que eran jóvenes, puesto que, como se mencionó anteriormente, la calidad de la cascara del huevo puede influir en este aspecto.

\section{DIAGNÓSTICO}

El primer paso para iniciar llegar al diagnóstico es realizar necropsias evaluando lesiones macroscópicas como pericarditis, peritonitis, perihepatitis y/o salpingitis, aunque estos hallazgos son muy generales, por lo tanto, el diagnostico debe confirmarse mediante el aislamiento a partir de sangre cardíaca o tejidos afectados, 
como hígado, bazo, pericardio y médula ósea; los medios selectivos como McConkey, eosina-metileno azul o agar drigalki son usados para su cultivo, la identificación adicional de las colonias se basa en reacciones bioquímicas como producción de indol, fermentación de glucosa con producción de gas, presencia de B-galactosidasa, ausencia de producción de sulfito de hidrógeno y ureasa, e incapacidad de usar citrato como fuente de carbono (Dho-Moulin y Fairbrother, 1999).

La membrana externa de E. coli está compuesta por lipopolisacáridos (LPS) que incluyen lípido $\mathrm{A}$, oligosacáridos centrales y un polisacárido único, denominado antígeno-O, algunos de los cuales han sido seleccionados como biomarcadores para su clasificación. El método diagnóstico de la O-serotipificación es de uso frecuente, siendo una herramienta valiosa en la evaluación epidemiológica, el análisis de riesgos y la prevención. La serotipificación molecular hace referencia a ensayos genéticos que se dirigen a genes específicos del grupo $O$ que se encuentran dentro de los grupos genéticos de E. coli. Existen métodos rápidos como ELISA basado en la detección de anticuerpos contra dos serotipos patógenos importantes de E. coli O78: K80 y O2: K1; también ELISA basado en el antígeno fimbrial, pero ambos tienen un valor limitado porque solo pueden detectar tipos de APEC homóloga (Fratamico et al., 2016).

La electroforesis en gel de campo pulsado (PFGE) es un método confiable y altamente discriminatorio y se ha considerado como el "estándar de oro" de los métodos de tipificación del genoma; también está disponible la tecnología de repeticiones palindrómicas cortas agrupadas y regularmente interespaciadas (CRISPR), que se basa en repeticiones de ADN cortas altamente conservadas separadas por secuencias únicas de longitud similar, y que se han utilizado para la subtipificación, identificación y detección de bacterias con base en el contenido la secuenciación de loci CRISPR. Los análisis de tipificado basados en CRISPR se pueden utilizar para la detección y diferenciación de cepas en investigaciones epidemiológicas (Shariat y Dudley, 2014). 


\section{Factores de riesgo}

El riesgo de colibacilosis aumenta con la contaminación del medio ambiente relacionado con un inadecuado manejo de la bioseguridad en la granja, puesto que la mala higiene del galpón, del personal, de los equipos y materiales, y la ausencia de fumigaciones rutinarias de las camas de los galpones para disminuir la carga bacteriana pueden predisponer a la enfermedad. Un ambiente desfavorable con exceso de amoníaco o polvo hace que el sistema respiratorio sea más susceptible a las infecciones por APEC, por ello es importante tener buena limpieza de las mallas, nidos, lámparas y todos los materiales que se encuentren en el galpón; el estado de la cama puede ser un riego de colonización rápida de la bacteria (Barnes y Gross, 1997). Otro factor a tener en cuenta es la sobrepoblación, y los cambios bruscos que se dan en el momento de la apertura o comienzo de la producción de las aves, porque hay contacto directo entre machos y hembras, y sí no se maneja adecuadamente la densidad de machos por metro cuadrado, se genera sobreapareamiento causando laceraciones en las gallinas y aumentando el riesgo de celulitis que conllevan a la septicemia.

También es importante la duración de la exposición, la virulencia propia de la cepa, la raza y el estado inmunológico del ave. Los daños causados en el sistema respiratorio por otro patógenos pueden favorecen la infección por APEC. EI consumo del agua en los animales es otro factor crítico, y ésta debe cumplir con estándares de calidad aceptados, con un adecuado manejo para que las concentraciones de bacterias totales y de coliformes no excedan 100 y 500 UFC/100 $\mathrm{ml}$ respectivamente.

Por otro lado, las deficiencias severas de los nutrientes requeridos pueden deteriorar la inmunidad del hospedero y por ende la resistencia a las enfermedades, es importante evaluar las condiciones de presentación e higiene del alimento suministrado a las aves, porque si no son las ideales se da lugar a alteraciones en la inmunidad del intestino y con ello favorecer la invasión de bacterias patógenas que producen daño a las aves. El manejo que se le da a la recogida del huevo de piso es importante para disminuir el riesgo de contaminación y colonización 
bacteriana que posteriormente lleva a muerte embrionaria o contaminación de la máquina de nacimiento.

\section{PREVENCIÓN}

Diferentes frentes deben ser abordados para lograr una eficaz prevención de las enfermedades, en primer lugar, disminuir la contaminación ambiental para minimizar el contacto con los patógenos, teniendo una adecuada infraestructura con zonas limpias y sucias, zonas para cambio de ropa y lavado de manos, adecuado manejo de las heces y control de plagas; además es de vital importancia controlar estrictamente factores como la densidad, humedad, ventilación, polvo y amoniaco. De otro lado el un buen manejo del huevo como la recogida a las horas correspondientes, uso de desinfectantes, fumigación de los huevos dentro de las dos horas posteriores a su postura y descarte de huevos fragmentados o aquellos con una contaminación fecal evidente (Barnes y Gross, 1997; Dho-Moulin y Fairbrother, 1999).

\section{Vacunas}

Las aves responden a las vacunas desarrollando respuestas inmunes humorales y celulares, la bolsa de Fabricio y el timo sirven como los principales órganos linfoides de su sistema inmune; las células B usan inmunoglobulinas de superficie como receptores de antígenos y se diferencian en células plasmáticas para secretar anticuerpos, se producen tres clases de inmunoglobulinas: $\lg \mathrm{M}, \lg \mathrm{G}$ e $\lg \mathrm{A}$, el éxito de la respuesta vacunal en una parvada generalmente se controla midiendo el aumento en los títulos de anticuerpos a los pocos días de la vacunación (Ghunaim et al., 2014).

Los esfuerzos para encontrar una vacuna eficaz contra las APEC se han centrado en el uso de bacterinas, posteriormente se desarrollaron las vacunas in vivo y luego las de subunidades. Se deben superar varios obstáculos al intentar diseñar una vacuna eficaz, en general deben ser capaces de inducir protección cruzada contra varios serogrupos de APEC, su administración debe ser masiva como en el agua potable, el alimento, in ovo o spray, por último se deben ser administradas a aves 
jóvenes para que desarrollen una inmunidad protectora (Dho-Moulin y Fairbrother, 1999; Ghunaim et al., 2014).

\section{PERSPECTIVA PROFESIONAL}

Los mecanismos subyacentes a la evolución y aparición de nuevos patógenos bacterianos no son suficientes para explicar la evolución de las cepas patogénicas de Escherichia coli. Se ha determinado que es una bacteria con una gran diversidad de genes polimórficos que presentan un ambiente detallado para ser estudiado, este polimorfismo define los factores de virulencia y los genes responsables de la diferenciación que presenta cada cepa, estos factores de virulencia son los responsables de la supervivencia del patógeno dentro del hospedero.

Se puede entender que hay tres tipos de contaminación posible en el ave, ya sea ingresando por vía respiratoria, translocación bacteriana en el intestino, o por el ingreso ascendente desde la cloaca al oviducto, conllevando a la muerte del ave y generando lesiones como pericarditis, perihepatitis, ooforitis, salpingitis, o en general una poliserositis, lesiones que pueden ser evidentes en la necropsia.

Dado que en la industria avícola se manejan sumas altas de dinero, es importante controlar los factores de riesgo que pueden resultar en brotes de $E$. coli mediante las buenas prácticas de manejo y la bioseguridad dentro de las instalaciones. Cuando hay infección pero sin evidencia clínica, se presentan problemas como bajos porcentajes de nacimientos, ventanas de nacimiento muy abiertas, aumento de mortalidad en pollitos de un día, que pueden llevar reclamos por parte de los clientes.

Un método de prevención contra la colibacilosis es la vacunación, que forma parte integral de los planes sanitarios de los lotes y las granjas. Los sistemas de administración de vacunas incluyen inyección in ovo, aerosol, pulverización, dilución en agua potable, colirio e inyección en la membrana del ala. Al entender el genoma de la bacteria se comprende la dificultad para crear una vacuna que responda ante diferentes cepas que se puedan presentar en campo; también se han hecho 
estudios para encontrar un medio de aspersión que le brinde una adecuada inmunidad a las aves.

\section{CONCLUSIÓN}

Es de vital importancia controlar los puntos de riesgo que presenta la granja, para disminuir la contaminación de las aves y de los subproductos, manteniendo buenos protocolos de bioseguridad, sanitización de los galpones, adecuado manejo de desechos de las aves, tiempos de retiros entre lotes, realizando control microbiológico del agua y de materias primas, ventilación de los galpones, inmunización de aves y capacitaciones a los operarios que manejan los animales.

\section{RECOMENDACIONES}

Realizar evaluaciones microbiológicas rutinarias a los elementos de los galpones, agua, alimento y mano de los operarios que manipulan las aves.

Llevar un reporte de los casos presentados en la granja a partir de la fecha del evento, edad del lote, etapa de producción, alimento suministrado, operario que maneja el lote y lo correspondiente a los hallazgos de necropsias, con el objetivo de valorar la presentación de la enfermedad, posibles causas y así determinar en qué puntos críticos se están fallando dentro de la granja.

Realizar un diagnóstico certero basado en las necropsias y análisis microbiológicos, y en lo posible aislamiento y genotipificación de la bacteria, puesto que las nuevas tecnologías facilitan una mejor compresión de la patogénesis microbiana.

Cuando se realicen tratamientos antibióticos sobre las aves se debe tener en cuenta que debido a su polimorfismo y variabilidad genética de E. coli su puede incrementar la presión de selección dando lugar a cepas con resistencia antibiótica.

\section{REFERENCIAS BIBLIOGRÁFICAS}

1. Barnes H., Nolan L., Vaillancourt J. Colibacillosis. En: Saif Y., Fadly A., McDougald L., Nolan L. y Swayne D. (Ed). Disease of Poultry. Blackwell Publishing, lowa, USA, p 691-737. 2008. 
2. Barnes J., Gross W. Colibacilosis. En: Calnek B. (Ed). Diseases of poultry. State University Press, Ames: lowa, p 131-141. 1997.

3. Breland E.J., Eberly A.R., Hadjifrangiskou M. An overview of two-component signal transduction systems implicated in extra-intestinal pathogenic $\mathrm{E}$. coli infections. Frontiers in Cellular and Infection Microbiology. 7 (Art. 162): 1-14. 2017.

4. Clermont O., Christenson J.K., Denamur E., Gordon D.M. The Clermont Escherichia coli phylo-typing method revisited: improvement of specificity and detection of new phylo-groups. Environmental Microbiology Reports. 5 (1): 5865. 2013.

5. Collingwood C., Kemmett K., Williams N., Wigley P. Is the concept of avian pathogenic Escherichia coli as a single pathotype fundamentally flawed? Frontiers in Veterinary Science. 1 (Art. 5): 1-4. 2014.

6. Collingwood C.R. Pathogenomic characterization of a novel, layer-associated Avian Pathogenic Escherichia coli, PhD. Universidad de Liverpool, Liverpool, Inglaterra. 176 p. 2016.

7. Croxen M.A., Law R.J., Scholz R., Keeney K.M., Wlodarska M., Finlay B.B. Recent advances in understanding enteric pathogenic Escherichia coli. Clinical Microbiology Reviews. 26 (4): 822-880. 2013.

8. Chaudhari A.A., Kariyawasam S. An experimental infection model for Escherichia coli egg peritonitis in layer chickens. Avian Diseases. 58 (1): 25-33. 2014.

9. De Reu K., Grijspeerdt K., Messens W., Heyndrickx M., Uyttendaele M., Debevere J., Herman L. Eggshell factors influencing eggshell penetration and whole egg contamination by different bacteria, including Salmonella enteritidis. International Journal of Food Microbiology. 112 (3): 253-260. 2006.

10. Dho-Moulin M., Fairbrother J.M. Avian pathogenic Escherichia coli (APEC). Veterinary Research, BioMed Central. 30 (2-3): 299-316. 1999.

11. Ewers C., Janßen T., Kießling S., Philipp H.-C., Wieler L.H. Molecular epidemiology of avian pathogenic Escherichia coli (APEC) isolated from colisepticemia in poultry. Veterinary Microbiology. 104 (1-2): 91-101. 2004.

12. Fratamico P.M., DebRoy C., Liu Y., Needleman D.S., Baranzoni G.M., Feng P. Advances in molecular serotyping and subtyping of Escherichia coli. Frontiers in Microbiology. 7 (Art. 644): 1-8. 2016.

13. Ghunaim H., Abu-Madi M.A., Kariyawasam S. Advances in vaccination against avian pathogenic Escherichia coli respiratory disease: potentials and limitations. Veterinary Microbiology. 172 (1-2): 13-22. 2014.

14. Gross W. Diseases due to Escherichia coli in poultry. En: Carlton L.G. (Ed). Escherichia coli in Domestic Animals and Man. CAB International, Wallingford, Connecticut, USA, p 237-259. 1994.

15. Guabiraba R., Schouler C. Avian colibacillosis: still many black holes. FEMS Microbiology Letters. 362 (15): fnv118. 2015.

16. Hacker J., Kaper J.B. Pathogenicity islands and the evolution of microbes. Annual Reviews in Microbiology. 54 (1): 641-679. 2000.

17. Huja S., Oren Y., Trost E., Brzuszkiewicz E., Biran D., Blom J., Goesmann A., Gottschalk G., Hacker J., Ron E.Z., Dobrindt U. Genomic avenue to avian colisepticemia. MBio. 6 (1): e01681-14. 2015. 
18. Jordan F., Williams N., Wattret A., Jones T. Observations on salpingitis, peritonitis and salpingoperitonitis in a layer breeder flock. Veterinary Record. 157 (19): 573-577. 2005.

19. Kaas R.S., Friis C., Ussery D.W., Aarestrup F.M. Estimating variation within the genes and inferring the phylogeny of 186 sequenced diverse Escherichia coli genomes. BMC genomics. 13 (1): 577. 2012.

20. Kariyawasam S., Johnson T.J., Nolan L.K. The pap operon of avian pathogenic Escherichia coli strain $\mathrm{O} 1: \mathrm{K} 1$ is located on a novel pathogenicity island. Infection and immunity. 74 (1): 744-749. 2006.

21. Kindt T.J., Goldsby R., Osborne B. Inmunología de Kuby. McGraw Hill, México. 695 p. 2007.

22. La Ragione R., Woodward M.J. Virulence factors of Escherichia coli serotypes associated with avian colisepticemia. Research in Veterinary Science. 73 (1): 27-35. 2002.

23. Landman W., Cornelissen R. Escherichia coli salpingitis and peritonitis in layer chickens: an overview. Tijdschrift Voor Diergeneeskunde. 131 (22): 814-822. 2006.

24. Landman W., Feberwee A., Mekkes D., Veldman K., Mevius D. A study on the vertical transmission of arthropathic and amyloidogenic Enterococcus faecalis. Avian Pathology. 28 (6): 559-566. 1999.

25. Lutful S., Hasan M., Alam J., Basu S., Yamasaki S. Colibacillosis and its impact on egg production. En: Hester P. (Ed). Egg Innovations and Strategies for Improvements. Academic PressElsevier, Londres, Inglaterra, p 523-535. 2017.

26. Mellata M., Dho-Moulin M., Dozois C.M., Curtiss III R., Lehoux B., Fairbrother J.M. Role of avian pathogenic Escherichia coli virulence factors in bacterial interaction with chicken heterophils and macrophages. Infection and Immunity. 71 (1): 494-503. 2003.

27. Monroy M.A., Knöbl T., Bottino J.A., Ferreira C.S.A., Ferreira A.J.P. Virulence characteristics of Escherichia coli isolates obtained from broiler breeders with salpingitis. Comparative Immunology, Microbiology and Infectious Diseases. 28 (1): 1-15. 2005.

28. Moulin M., Répérant M., Laurent S., Brée A., Mignon S., Germon P., Rasschaert D., Schouler C. Extraintestinal pathogenic Escherichia coli strains of avian and human origin: link between phylogenetic relationships and common virulence patterns. Journal of Clinical Microbiology. 45 (10): 3366-3376. 2007.

29. Nakazato G., Campos T.A.d., Stehling E.G., Brocchi M., Silveira W.D.d. Virulence factors of avian pathogenic Escherichia coli (APEC). Pesquisa Veterinária Brasileira. 29 (7): 479-486. 2009.

30. Olsen R., Frantzen C., Christensen H., Bisgaard M. An investigation on firstweek mortality in layers. Avian Diseases. 56 (1): 51-57. 2012.

31. Ozaki H., Murase T. Multiple routes of entry for Escherichia coli causing colibacillosis in commercial layer chickens. Journal of Veterinary Medical Science. 71 (12): 1685-1689. 2009.

32. Petersen A., Christensen J.P., Kuhnert P., Bisgaard M., Olsen J.E. Vertical transmission of a fluoroquinolone-resistant Escherichia coli within an integrated broiler operation. Veterinary Microbiology, 116 (1-3): 120-128. 2006. 
33. Piercy D., West B. Experimental Escherichia coli infection in broiler chickens: course of the disease induced by inoculation via the air sac route. Journal of Comparative Pathology, 86 (2): 203-210. 1976.

34. Poulsen L.L., Thøfner I., Bisgaard M., Christensen J.P., Olsen R.H., Christensen $\mathrm{H}$. Longitudinal study of transmission of Escherichia coli from broiler breeders to broilers. Veterinary Microbiology. 207: 13-18. 2017.

35. Pourbakhsh S.A., Boulianne M., Martineau B., Dozois C.M., Desautels C., Fairbrother J.M. Dynamics of Escherichia coli infection in experimentally inoculated chickens. Avian Diseases. 41 (1): 221-233. 1997.

36. Roberts J., Souillard R., Bertin J. Avian diseases which affect egg production and quality. En: (Ed). Improving the Safety and Quality of Eggs and Egg Products: Egg Chemistry, Production and Consumption. Woodhead Publishing Limited, p 376-393. 2011.

37. Russo T.A., Johnson J.R. Proposal for a new inclusive designation for extraintestinal pathogenic isolates of Escherichia coli: ExPEC. The Journal of infectious diseases. 181 (5): 1753-1754. 2000.

38. Shariat N., Dudley E.G. CRISPRs: molecular signatures used for pathogen subtyping. Applied and Environmental Microbiology. 80 (2): 430-439. 2014.

39. Sun H., Liu P., Nolan L.K., Lamont S.J. Thymus transcriptome reveals novel pathways in response to avian pathogenic Escherichia coli infection. Poultry science. 95 (12): 2803-2814. 2016.

40. Touchon M., Hoede C., Tenaillon O., Barbe V., Baeriswyl S., Bidet P., Bingen E., Bonacorsi S., Bouchier C., Bouvet O., Calteau A., Chiapello H., Clermont O., Cruveiller S., Danchin A., Diard M., Dossat C., El Karoui M., Frapy E., Garry L., Ghigo J.M., Gilles A.M., Johnson J., Le Bouguénec C., Lescat M., Mangenot S., Martinez V., Matic I., Nassif X., Oztas S., Petit M.A., Pichon C., Rouy Z., Saint Ruf C., Schneider D., Tourret J., Vacherie B., Vallenet D., Médigue C., Rocha E., Denamur E. Organised genome dynamics in the Escherichia coli species results in highly diverse adaptive paths. PLoS genetics. 5 (1): e1000344. 2009.

41. Waldron K.J., Rutherford J.C., Ford D., Robinson N.J. Metalloproteins and metal sensing. Nature. 460: 823-830. 2009.

42. Wang C., Pors S.E., Olsen R.H., Bojesen A.M. Transmission and pathogenicity of Gallibacterium anatis and Escherichia coli in embryonated eggs. Veterinary Microbiology. 217: 76-81. 2018.

43. Wright K.J., Hultgren S.J. Sticky fibers and uropathogenesis: bacterial adhesins in the urinary tract. Future Medicine. 1 (1): 75-87. 2006.

44. Yassin H., Velthuis A.G., Boerjan M., van Riel J. Field study on broilers' firstweek mortality. Poultry Science. 88 (4): 798-804. 2009.

45. Yoder J.A., Litman G.W. The phylogenetic origins of natural killer receptors and recognition: relationships, possibilities, and realities. Immunogenetics. 63 (3): 123-141. 2011.

46.Zhuang Q.-Y., Wang S.-C., Li J.-P., Liu D., Liu S., Jiang W.-M., Chen J.-M. A clinical survey of common avian infectious diseases in China. Avian Diseases. 58 (2): 297-302. 2014. 